OPEN ACCESS

Edited by:

Edward J. Lesnefsky,

Virginia Commonwealth University and McGuire Veterans Affairs Medical

Center, USA

Reviewed by:

James A. Stewart Jr.

Mississippi State University, USA Jun Yoshioka,

Brigham and Women's Hospital and

Harvard Medical School, USA

*Correspondence:

Siva Kumar Panguluri spangulu@health.usf.edu

Specialty section:

This article was submitted to Cardiovascular Genetics and

Systems Medicine,

a section of the journal

Frontiers in Cardiovascular Medicine

Received: 27 July 2015 Accepted: 19 November 2015 Published: 11 December 2015

Citation:

Kakoti BB, Hernandez-Ontiveros DG, Kataki MS, Shah K, Pathak Y and Panguluri SK (2015) Resveratrol and Omega-3 Fatty Acid: Its Implications in Cardiovascular Diseases.

Front. Cardiovasc. Med. 2:38. doi: 10.3389/fcvm.2015.00038

\section{Resveratrol and Omega-3 Fatty Acid: Its Implications in Cardiovascular Diseases}

\author{
Bibhuti Bhusan Kakoti', Diana G. Hernandez-Ontiveros ${ }^{2}$, Manjir Sarma Kataki', \\ Kajri Shah ${ }^{2}$, Yashwant Pathak ${ }^{2}$ and Siva Kumar Panguluri* \\ ${ }^{1}$ Department of Pharmaceutical Sciences, Dibrugarh University, Assam, India, ${ }^{2}$ College of Pharmacy, University of South \\ Florida, Tampa, FL, USA
}

The present review aims at summarizing the major therapeutic roles of resveratrol and omega-3 fatty acids (O3FAs) along with their related pathways. This article reviews some of the key studies involving the health benefits of resveratrol and O3FAs. Oxidative stress has been considered as one of the most important pathophysiological factors associated with various cardiovascular disease conditions. Resveratrol, with the potent antioxidant and free radical scavenging properties, has been proven to be a significantly protective compound in restoring the normal cardiac health. A plethora of research also demonstrated the reduction of the risk of coronary heart disease, hypertension, and stroke, and their complications by O3FAs derived from fish and fish oils. This review describes the potential cardioprotective role of resveratrol and O3FAs in ameliorating the endoplasmic reticulum stress.

Keywords: resveratrol, omega-3 fatty acid, oxidative stress, endoplasmic reticulum stress, cardiovascular diseases, coronary artery diseases

\section{INTRODUCTION}

Cardiovascular complications continue to be among the list of leading causes of death worldwide. According to centers for disease control and prevention (CDC) reports, more than half a million people in the USA die of heart disease every year, one in every four deaths every year (1). Increasing evidences suggest that metabolic syndrome constitutes a significant risk for cardiovascular diseases, which can also cause type 2 diabetes, obesity, and oxidative stress $(2,3)$. Effective tactics to reduce these conditions include immediate weight loss (4), and long-term dietary strategies enhancing health by maintaining the body weight (5). There are multiple non-pharmacological approaches, such as alternative medicine, that have the potential to reduce cardiovascular risks; resveratrol and omega-3 fatty acid (O3FA) are two well-known natural products that come under this category.

Resveratrol is chemically trans-3,5,4' -trihydroxystilbene. It is a polyphenol phytoalexin compound naturally abundant in a variety of plant species, including white hellebore (Veratrum grandiflorum $O$. Loes), Japanese knotweed (Polygonum cuspidatum), grapes, blueberries, peanuts, wine, and mulberries $(6,7)$. Resveratrol came into the limelight following the discovery of the cardioprotective nature of red wine (8). This has paved the way for new research activities involving clinical health benefits of resveratrol. A growing body of research therefore indicated that resveratrol could improve a wide variety of disease conditions, including cardiovascular diseases, cancer, ischemic disorders, and neurodegenerative disorders (9). It is also postulated that resveratrol can increase the stress resistance 
and also slow down the aging process to increase the life span in diverse organisms from microorganisms to vertebrates (6).

Resveratrol is one of the well-known natural compounds, which is well-studied for its free radical scavenger and antioxidant properties. It can modulate various intracellular signal transduction pathways and demonstrate therapeutic effects, including cell survival, modulation of apoptosis, and angiogenesis $(10,11)$. Growing evidences suggests the anti-cancer activity of resveratrol and its potential as a therapeutic as well as a chemo-preventive agent (12). Scientific outcomes demonstrated the potential use of resveratrol in various cancers (13-25). However, pre-clinical results were not well reflected in clinical studies in human. It may be due to the pharmacokinetic issues pertaining to resveratrol. It is lipophilic in nature and has a short half-life as well.

The use of O3FAs as a widespread alternative has been practiced globally by many societies. O3FAs are essential for normal growth and development of the nervous system. The benefits of O3FA have been documented in the past 35 years (26-28). All these research data strongly support the use of O3FAs in reducing the risk of cardiac diseases.

The purpose of this review is to summarize the major antioxidant role of resveratrol and O3FA along with their related pathways and highlight promising therapeutic approaches. The benefits of combinational therapy with these two natural compounds were also discussed.

\section{RESVERATROL AND THE ENDOPLASMIC RETICULUM STRESS}

The endoplasmic reticulum (ER) is a significant but complex intracellular organelle in the physiological system. It is a vital organelle involved in modification and synthesis of proteins, translational processes, and fabrication at the post-translational level. Physiologically, the integrity of ER is maintained for proper cellular functioning. Any stimuli from diverse origin can influence the ER environment and generate disturbance in terms of nutritional deficiency leading to a compromised pathological status. The stimuli can be of physiological and biochemical origin, which can produce moderate-to-severe abnormalities, including alterations in glycosylation, depletion of calcium stores, oxidative stress conditions, DNA damage, and other pathological conditions. These alternations generally produce a severe pathological stress condition in the ER known as ER stress or ER oxidative stress. This pathological stress is coexisted with the abnormal protein accumulations in the ER.

Many reports from animal and human studies have shown that oxygen deprivation in the heart causes ER stress of myocytes by accumulating unfolded and misfolded proteins, thereby triggering apoptosis (29-32). Also, the research data showed that ER stress may play a crucial role in the elevation of atherosclerotic plaque (33-35). Furthermore, recent evidences also suggest that a transcriptional factor, nuclear factor-E2-related factor (Nrf2), may play a central role to compensate ER stress conditions (36). This Nrf2 signaling has shown to upregulate the expression of proteasomal catalytic sub-units in several cell types, thereby contributing to the ER stress response by enhancing proteasomal-mediated ER-associated degradation (37). Other studies also suggest that interventions against ER stress and activation of Nrf2 significantly reduce myocardial infarct size in animals exposed to I/R injury and also reduce cardiac hypertrophy in heart failure animal models (38).

\section{RESVERATROL AS A CARDIOPROTECTIVE AGENT}

Resveratrol has shown beneficial and protective effects against most degenerative and cardiovascular diseases, including ischemia/reperfusion injury, atherosclerosis, hypertension, and heart failure. The adaptive response through the preconditioning-like action of resveratrol is linked with the cardioprotective effects of the compound. With the expression of cardioprotective genes and proteins, such as heat shock and antioxidant proteins, resveratrol demonstrated an adaptive stress response as the preconditioning (39). These effects of resveratrol have been correlated with the modulation of mTORRictor survival pathways (40). Results of several in vitro and in vivo studies of resveratrol in animal models suggested LDL oxidation inhibition, suppression of aggregation of platelets, and reduction of ischemia-reperfusion-induced myocardial injury, which in turn indicated the promising cardiovascular protective effects of resveratrol (41-43). Resveratrol also revealed anti-inflammatory activity, which was postulated to be linked with nitric oxide (NO) production. This study also demonstrated cardioprotective action of resveratrol by inhibiting toll-like receptor 4 (TLR4)/NF- $\mathrm{KB}$ signaling pathway in a rat model of myocardial ischemia and reperfusion (MI/R) (44). Another very common cardiovascular disease is stroke, which is one of the main causative factors of deaths throughout the world population. Scientific investigations suggest oxidative stress as the predominant pathophysiological modality associated with stroke $(45,46)$. Recent data also suggest that the ability of resveratrol in ameliorating the oxidative stress conditions might be due to the aggravation of NO production along with its anti-inflammatory activity (47). Studies also suggested several mechanisms of action for resveratrol to justify its cardioprotective actions $(48,49)$. Resveratrol was also found to be protective against the cardio toxicity induced by the potent anti-cancer agent doxorubicin (50). These authors showed that resveratrol restored the mitochondrial structure as evident from the electron microscope examinations. A recent pre-clinical study also suggested that resveratrol alleviate the cardio toxicity induced by doxorubicin (51).

\section{ROLE OF OMEGA-3 FATTY ACIDS AS ANTIOXIDANT AGENTS IN CARDIOVASCULAR DISEASES}

Two well-known fish/fish oil-derived O3FA are the eicosapentanoic acid (EPA) and docosahexanoic acid (DHA). DHA and EPA are vital nutrients required for brain and retina growth in order to have normal neuronal functioning and vision. These two 
in turn help humans develop their learning and mental abilities throughout life. These fatty acids are by-products derived from the metabolic conversion of the amino acid alanine (ALA) in the liver (52). Yet, human intake of O3FA is limited; they are not abundant in vegetables and grain food sources, and thus, they have to be supplemented directly. In addition, the metabolic change of alanine (ALA) to DHA/EPA in the body is limited; therefore, it is recommended to have sufficient amounts of fish, or O3FA directly as a dietary supplement.

The American Heart Association recommends $130 \mathrm{mg} /$ day of DHA/EPA (combined), for people suffering from coronary heart disease. Various studies have indicated the benefits of fish consumption containing the O3FA, EPA/DHA, and lowering the risk of cardiovascular conditions, such as fatal heart attack, high cholesterol, and stroke (53-57). Yet, the signal transduction pathways and mechanisms associated with it and how they function have not fully been revealed.

\section{MECHANISMS ASSOCIATED WITH O3FA}

Omega-3 fatty acids seem to have versatile properties with no significant drug interactions. The suggested mechanisms associated with the benefits of O3FA are stabilization of plaque formation, improving lipid profile, normalizing blood pressure, and anti-inflammatory and anti-arrhythmic properties (58). Nevertheless, there is still a major controversy over O3FA having benefits against arrhythmias, which was suggested by the Italian GISSI-Prevenzione study (59). The exact mechanism of its action in reducing cardiovascular risk is yet to be understood.

\section{O3FA AND OXIDATIVE STRESS}

One of the valuable properties of O3FAs is their antioxidative action. They seem to induce cardioprotection by ameliorating oxidative stress. Oxidative stress causes damage by the production of radicals that distress normal metabolic cell functioning by destroying lipids, proteins, and nucleic acids. Radical accumulation eventually causes structural cell membrane damage, vascular endothelial dysfunction, and cell death, often leading to cardiovascular diseases (60). A recent study in rats evaluated the combined effects of intermittent hypobaric hypoxia (IH) and O3FA on cardiac function, oxidative balance, and inflammatory state. Their findings showed that animals under IH have improved left ventricular function, reduced oxidative stress, and increased antioxidant enzyme expression when compared to the normobaric normoxia group. Supplementation of O3FA showed similar results to that of the IH group, suggesting that both conditions, $\mathrm{IH}$ and O3FA, induce functional improvement by antioxidant and anti-inflammatory mechanisms, thereby establishing cardioprotection (61).

Furthermore, another protective action of O3FA is to reinforce the body's antioxidant defenses to improve cardiac function. Recent data suggest that DHA and EPA regulate cell membrane fluidity, organization, and permeability that affect signaling pathways and diffusion processes, with positive effects on key cardiovascular pathways (62). In addition, O3FAs manage to exert anti-inflammatory properties by controlling the synthesis of immune mediators (e.g., thromboxanes, prostaglandins, and leukotrienes) in murine cell lines and human primary monocytederived macrophages (63-65). These mediator molecules change the arachidonic acid metabolic pathway of prostaglandin E2 (PGE2), via the activation of cytosolic phospholipase A2 (cPLA2), cyclooxygenase 2 (COX-2), and the production of PGE2, as a cPLA2 inhibitor, and reduce other pro-inflammatory molecules in the heart (e.g., IL-1 and IL-6) (63). Also, a high O3FA enriched diet has shown benefits in a rat model with cardiac ischemia-reperfusion injury (66).

Furthermore, specific types of O3FAs can affect oxidative stress due to disparities in their chemical predisposition to oxidation. Experiments by Bellido et al. (67) showed an increase in activation of a redox-sensitive transcriptional factor, NF- $\kappa \mathrm{B}$, in peripheral blood mononuclear cells following a meal high in butter or walnuts but not olive oil (67). These experiments are interesting and require further expansion to determine specific fatty acid effects, and any other meals specifically enriched with O3FA.

\section{RESVERATROL AND O3FA COMBINED EFFECT}

Many in vivo and in vitro studies testing the combined effects of O3FA and resveratrol have shown them to have synergistic effects on inflammation. For example, a recent study by Schwager et al. (68) showed that the LPS-stimulated peripheral leukocytes and IL-1-activated human chondrocytes treated only with resveratrol significantly reduced levels of prostaglandin 2 (PGE2), CCL5/ RANTES, and CXCL8/IL-8, but increased IL-1 $\beta$, IL-6, and IL-10, whereas O3FA treatment increased the levels of PGE2 and CXCL8/IL-8. Surprisingly, their combined administration exerted joint effects on CCL5/RANTES and IL-6 or CXCL8/IL-8 (68). Thus, O3FA and resveratrol act together on inflammatory mediators when dealing with acute and chronic inflammation of chondrocytes, but not on acute inflammation of peripheral leukocytes. In diseases where chronic inflammation occurs, such as osteoarthritis, O3FA and resveratrol may be beneficial. In vitro studies of chronic inflammation implementing long-term treatment of these two have shown a reduction in the production of inflammatory mediators. For example, bovine chondrocytes and cartilage explants have identified that long-term in vitro treatment of chondrocytes with conjugated linoleic acids or EPA mitigated the production of $\mathrm{PGE}_{2}$ and nitric oxide (69). Also, other studies reported reduced mRNA levels of matrix metalloproteinaises (MMPs), a disintegrin and metalloproteinase with thrombospondin motifs 4 (ADAMTS-4), and interleukins (68, 70). Thus, resveratrol and O3FA are able to reduce the inflammatory processes during chronic inflammation. But, in instances of acute inflammation, resveratrol acts to reduce early inflammatory events, whereas O3FA has the opposite effect and increases inflammatory events.

In an attempt to identify an effective therapy for cardiovascular patients, Hobbs et al. (71) did a pilot study with a multi-ingredient supplement (MIS) featuring blend of red yeast 


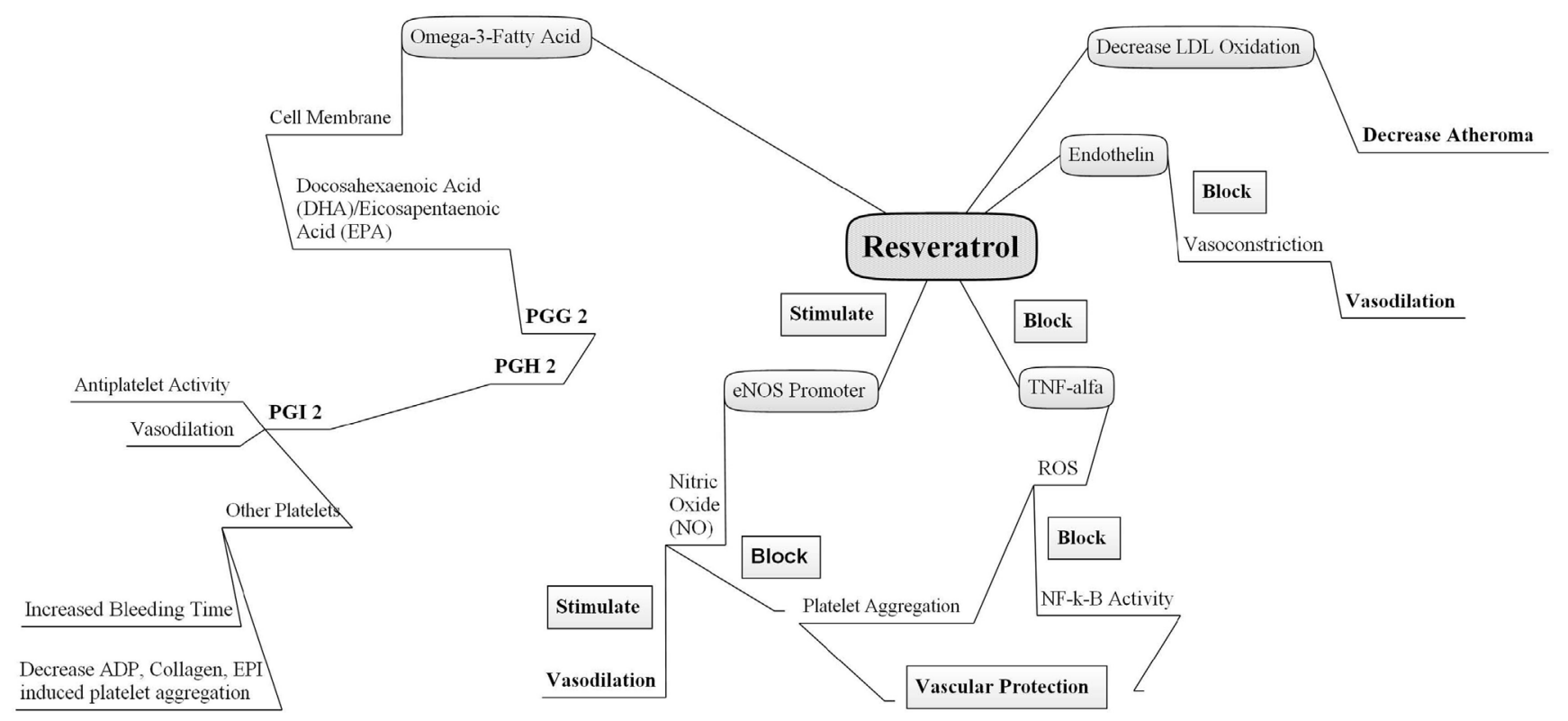

FIGURE 1 | Mechanisms of action of omega-3 fatty acid and resveratrol. Two natural cardioprotective compounds act independently via different pathways combination of both may offer beneficial effects. $\mathrm{PGG}_{2}$, prostaglandin $\mathrm{G}_{2}$; $\mathrm{PGH}_{2}$, prostaglandin $\mathrm{H}_{2}$; $\mathrm{PG} \mathrm{I}_{2}$, prostaglandin $\mathrm{I}_{2}$ or prostacyclin; eNOS, endothelial nitric oxide synthase; NO, nitric oxide, TNF-alpha, tissue necrotic factor alpha; ROS, reactive oxygen species; LDL, low density lipoprotein; ADP, adenosine diphosphate; $\mathrm{NF}-\kappa \mathrm{B}$, nuclear factor kappa B.

rice, bioflavonoids, polycosanol, and resveratrol along with a high-potency omega-3 polyunsaturated fatty acid in 19 patients with hypercholesterolemia (71). They found that the MIS supplement offers a promising result for cholesterol management by decreasing total cholesterol and LDL significantly. A separate review by the World Health Organization (72) found that the Mediterranean diet $(\mathrm{MeDi})$ is a promising strategy to prevent diseases such as cerebro- and cardiovascular diseases, cancer, respiratory diseases, diabetes, and neurodegenerative diseases, thereby improving life quality (72). The two major components in $\mathrm{MeDi}$ in this study are long-chain O3FAs derived from fish and resveratrol from plant phenols. The MeDi benefits have been studied in many human epidemiological studies suffering from cancer, cardiovascular conditions (myocardial infarction, stroke, angina pectoris, coronary bypass, and coronary angioplasty), and neurodegenerative diseases such as Alzheimer's disease (AD) (73-76). Also, a recent long-term randomized clinical trial (RCT) in 334 participants with high cardiovascular risk at a mean age of 67 years (PREDIMED study) reported positive effects of MeDi $(77,78)$.

From these studies, it is evident that the combinational therapy with O3FAs and resveratrol is more beneficial, and therefore, more studies should be directed to understand more insight on their mechanism of action at a molecular level.

\section{REFERENCES}

1. Centers for Disease Control and Prevention ; National Center for Health Statistics. Underlying Cause of Death 1999-2013. Data Are from the Multiple Cause of Death Files, 1999-2013, as Compiled from Data Provided by the 57 Vital Statistics Jurisdictions Through the Vital Statistics Cooperative Program (2015). Available from: http://wonder.cdc.gov/ucd-icd10.html

\section{CONCLUSION}

Based on the existing literature discussed in this review, it is evident that resveratrol and O3FAs are reported to be significantly protective and play crucial roles in the prevention of not only various cardiovascular diseases but also a variety of other diseases, including Alzheimer disease, cancer, diabetes, and inflammation (Figure 1). Resveratrol and O3FAs, with their unique antioxidant properties and cardioprotective nature, are demonstrated to be highly functional and beneficial ingredients in various functional foods, although the number of studies in terms of dosage regimens and pharmacokinetics profiles of these ingredients is scanty and newer studies should be initiated to profile the same. The growing body of scientific literatures indicated the potential health benefits of these functional ingredients. However, new mechanistic studies should be designed to evaluate and identify the mechanisms behind the observed fascinating beneficial outcomes of resveratrol and O3FAs along with their combinational benefits.

\section{FUNDING}

This work was supported by University of South Florida, College of Pharmacy startup funds (USF COP Startup funds) to Dr. Panguluri.

2. Dandona P, Aljada A, Chaudhuri A, Mohanty P, Garg R. Metabolic syndrome: a comprehensive perspective based on interactions between obesity, diabetes, and inflammation. Circulation (2005) 111:1448-54. doi:10.1161/01. CIR.0000158483.13093.9D

3. Peairs AD, Rankin JW, Lee YW. Effects of acute ingestion of different fats on oxidative stress and inflammation in overweight and obese adults. Nutr J (2011) 10:122. doi:10.1186/1475-2891-10-122 
4. Basu A, Devaraj S, Jialal I. Dietary factors that promote or retard inflammation. Arterioscler Thromb Vasc Biol (2006) 26:995-1001. doi:10.1161/01. ATV.0000214295.86079.d1

5. Wing RR, Phelan S. Long-term weight loss maintenance. Am J Clin Nutr (2005) 82:222S-5S.

6. Spanier G, Xu H, Xia N, Tobias S, Deng S, Wojnowski L, et al. Resveratrol reduces endothelial oxidative stress by modulating the gene expression of superoxide dismutase 1 (SOD1), glutathione peroxidase 1 (GPX1) and Nadph oxidase subunit (NOX4). J Physiol Pharmacol (2009) 60:111-6.

7. Borrelli F, Capasso R, Izzo AA. Garlic (Allium sativum L.): adverse effects and drug interactions in humans. Mol Nutr Food Res (2007) 51:1386-97. doi:10.1002/mnfr.200700072

8. Vidavalur R, Otani H, Singal PK, Maulik N. Significance of wine and resveratrol in cardiovascular disease: French paradox revisited. Exp Clin Cardiol (2006) 11:217-25.

9. Yang T, Wang L, Zhu M, Zhang L, Yan L. Properties and molecular mechanisms of resveratrol: a review. Pharmazie (2015) 70:501-6. doi:10.1691/ ph.2015.5571

10. Nie S, Xing Y, Kim GJ, Simons JW. Nanotechnology applications in cancer. Annu Rev Biomed Eng (2007) 9:257-88. doi:10.1146/annurev. bioeng.9.060906.152025

11. Niemeyer CM. Semi-synthetic nucleic acid-protein conjugates: applications in life sciences and nanobiotechnology. J Biotechnol (2001) 82:47-66. doi:10.1016/S1389-0352(01)00027-7

12. Nishiyama N. Nanomedicine: nanocarriers shape up for long life. Nat Nanotechnol (2007) 2:203-4. doi:10.1038/nnano.2007.88

13. Shutava TG, Balkundi SS, Vangala P, Steffan JJ, Bigelow RL, Cardelli JA, et al. Layer-by-layer-coated gelatin nanoparticles as a vehicle for delivery of natural polyphenols. ACS Nano (2009) 3:1877-85. doi:10.1021/nn900451a

14. Ferrari M. Cancer nanotechnology: opportunities and challenges. Nat Rev Cancer (2005) 5:161-71. doi:10.1038/nrc1566

15. Wang X, Yang L, Chen ZG, Shin DM. Application of nanotechnology in cancer therapy and imaging. CA Cancer J Clin (2008) 58:97-110. doi:10.3322/ CA.2007.0003

16. McNeil SE. Nanoparticle therapeutics: a personal perspective. Wiley Interdiscip Rev Nanomed Nanobiotechnol (2009) 1:264-71. doi:10.1002/wnan.6

17. Jagtap S, Meganathan K, Wagh V, Winkler J, Hescheler J, Sachinidis A. Chemoprotective mechanism of the natural compounds, epigallocatechin-3-O-gallate, quercetin and curcumin against cancer and cardiovascular diseases.CurrMedChem(2009) 16:1451-62.doi:10.2174/092986709787909578

18. Lee KW, Bode AM, Dong Z. Molecular targets of phytochemicals for cancer prevention. Nat Rev Cancer (2011) 11:211-8. doi:10.1038/nrc3017

19. Nair HB, Sung B, Yadav VR, Kannappan R, Chaturvedi MM, Aggarwal BB. Delivery of antiinflammatory nutraceuticals by nanoparticles for the prevention and treatment of cancer. Biochem Pharmacol (2010) 80:1833-43. doi:10.1016/j.bcp.2010.07.021

20. Siddiqui IA, Adhami VM, Bharali DJ, Hafeez BB, Asim M, Khwaja SI, et al. Introducing nanochemoprevention as a novel approach for cancer control: proof of principle with green tea polyphenol epigallocatechin-3-gallate. Cancer Res (2009) 69:1712-6. doi:10.1158/0008-5472.CAN-08-3978

21. Barras A, Mezzetti A, Richard A, Lazzaroni S, Roux S, Melnyk P, et al. Formulation and characterization of polyphenol-loaded lipid nanocapsules. Int J Pharm (2009) 379:270-7. doi:10.1016/j.ijpharm.2009.05.054

22. Sanna V, Pintus G, Roggio AM, Punzoni S, Posadino AM, Arca A, et al. Targeted biocompatible nanoparticles for the delivery of (-)-epigallocatechin 3-gallate to prostate cancer cells. J Med Chem (2011) 54:1321-32. doi:10.1021/ jm1013715

23. Yadav VR, Aggarwal BB. Curcumin: a component of the golden spice, targets multiple angiogenic pathways. Cancer Biol Ther (2011) 11:236-41. doi:10.4161/cbt.11.2.14405

24. Dube A, Nicolazzo JA, Larson I. Chitosan nanoparticles enhance the intestinal absorption of the green tea catechins (+)-catechin and (-)-epigallocatechingallate. Eur J Pharm Sci (2010) 41:219. doi:10.1016/j.ejps.2010.06.010

25. Carter LG, D’Orazio JA, Pearson KJ. Resveratrol and cancer: focus on in vivo evidence. Endocr Relat Cancer (2014) 21:R209-25. doi:10.1530/ ERC-13-0171

26. Buckley JD, Howe PR. Long-chain omega-3 polyunsaturated fatty acids may be beneficial for reducing obesity - a review. Nutrients (2010) 2:1212-30. doi:10.3390/nu2121212
27. Bourre JM. Roles of unsaturated fatty acids (especially omega-3 fatty acids) in the brain at various ages and during ageing. J Nutr Health Aging (2004) 8:163-74. doi:10.1186/1476-511X-3-25

28. Holman RT. The slow discovery of the importance of omega 3 essential fatty acids in human health. J Nutr (1998) 128:427S-33S.

29. Thuerauf DJ, Marcinko M, Gude N, Rubio M, Sussman MA, Glembotski CC. Activation of the unfolded protein response in infarcted mouse heart and hypoxic cultured cardiac myocytes. Circ Res (2006) 99:275-82. doi:10.1161/01. RES.0000233317.70421.03

30. Pan YX, Lin L, Ren AJ, Pan XJ, Chen H, Tang CS, et al. HSP70 and GRP78 induced by endothelin-1 pretreatment enhance tolerance to hypoxia in cultured neonatal rat cardiomyocytes. J Cardiovasc Pharmacol (2004) 44(Suppl 1):S117-20. doi:10.1097/01.fjc.0000166234.11336.a9

31. Vitadello M, Penzo D, Petronilli V, Michieli G, Gomirato S, Menabo R, et al. Overexpression of the stress protein Grp94 reduces cardiomyocyte necrosis due to calcium overload and simulated ischemia. FASEB J (2003) 17:923-5. doi:10.1096/fj.02-0644fje

32. Severino A, Campioni M, Straino S, Salloum FN, Schmidt N, Herbrand U, et al. Identification of protein disulfide isomerase as a cardiomyocyte survival factor in ischemic cardiomyopathy. J Am Coll Cardiol (2007) 50:1029-37. doi:10.1016/j.jacc.2007.06.006

33. Feng B, Yao PM, Li Y, Devlin CM, Zhang D, Harding HP, et al. The endoplasmic reticulum is the site of cholesterol-induced cytotoxicity in macrophages. Nat Cell Biol (2003) 5:781-92. doi:10.1038/ncb1035

34. Zhou J, Lhoták Š, Hilditch BA, Austin RC. Activation of the unfolded protein response occurs at all stages of atherosclerotic lesion development in apolipoprotein E-deficient mice. Circulation (2005) 111:1814-21. doi:10.1161/01 CIR.0000160864.31351.C1

35. Myoishi M, Hao H, Minamino T, Watanabe K, Nishihira K, Hatakeyama $\mathrm{K}$, et al. Increased endoplasmic reticulum stress in atherosclerotic plaques associated with acute coronary syndrome. Circulation (2007) 116:1226-33. doi:10.1161/CIRCULATIONAHA.106.682054

36. Digaleh H, Kiaei M, Khodagholi F. Nrf2 and Nrf1 signaling and ER stress crosstalk: implication for proteasomal degradation and autophagy. Cell Mol Life Sci (2013) 70:4681-94. doi:10.1007/s00018-013-1409-y

37. Lee S, Hur EG, Ryoo IG, Jung KA, Kwak J, Kwak MK. Involvement of the Nrf2-proteasome pathway in the endoplasmic reticulum stress response in pancreatic beta-cells. Toxicol Appl Pharmacol (2012) 264:431-8. doi:10.1016/j. taap.2012.08.021

38. Cominacini L, Mozzini C, Garbin U, Pasini A, Stranieri C, Solani E, et al. Endoplasmic reticulum stress and Nrf2 signaling in cardiovascular diseases. Free Radic Biol Med (2015) 88(Pt B):233-42. doi:10.1016/j. freeradbiomed.2015.05.027

39. Petrovski G, Gurusamy N, Das DK. Resveratrol in cardiovascular health and disease. Ann N Y Acad Sci (2011) 1215:22-33. doi:10.1111/j.1749-6632.2010.05843.x

40. Gurusamy N, Lekli I, Mukherjee S, Ray D, Ahsan MK, Gherghiceanu M, et al. Cardioprotection by resveratrol: a novel mechanism via autophagy involving the mTORC2 pathway. Cardiovasc Res (2010) 86:103-12. doi:10.1093/cvr/ cvp384

41. Bradamante S, Barenghi L, Villa A. Cardiovascular protective effects of resveratrol. Cardiovasc Drug Rev (2004) 22:169-88. doi:10.1111/j.1527-3466.2004. tb00139.x

42. Wu JM, Wang ZR, Hsieh TC, Bruder JL, Zou JG, Huang YZ. Mechanism of cardioprotection by resveratrol, a phenolic antioxidant present in red wine (review). Int J Mol Med (2001) 8:3-17. doi:10.3892/ijmm.8.1.3

43. Tang PC, NG YF, HO S, Gyda M, Chan SW. Resveratrol and cardiovascular health - promising therapeutic or hopeless illusion? Pharmacol Res (2014) 90:88-115. doi:10.1016/j.phrs.2014.08.001

44. Li J, Xie C, Zhuang J, Li H, Yao Y, Shao C, et al. Resveratrol attenuates inflammation in the rat heart subjected to ischemia-reperfusion: role of the TLR4/NF-kappaB signaling pathway. Mol Med Rep (2015) 11(2):1120-6. doi: $10.3892 / \mathrm{mmr} .2014 .2955$

45. Weaver J, Liu KJ. Does normobaric hyperoxia increase oxidative stress in acute ischemic stroke? A critical review of the literature. Med Gas Res (2015) 5:015-0032. doi:10.1186/s13618-015-0032-4

46. Saita E, Kondo K, Momiyama Y. Anti-inflammatory diet for atherosclerosis and coronary artery disease: antioxidant foods. Clin Med Insights Cardiol (2015) 8:61-5. doi:10.4137/CMC.S17071 
47. Nabavi SF, Li H, Daglia M, Nabavi SM. Resveratrol and stroke: from chemistry to medicine. Curr Neurovasc Res (2014) 11:390-7. doi:10.2174/15672026116 66140912114833

48. Lippi G, Franchini M, Favaloro EJ, Targher G. Moderate red wine consumption and cardiovascular disease risk: beyond the "French paradox". Semin Thromb Hemost (2010) 36:59-70. doi:10.1055/s-0030-1248725

49. Fagherazzi G, Vilier A, Lajous M, Boutron-Ruault MC, Balkau B, ClavelChapelon F, et al. Wine consumption throughout life is inversely associated with type 2 diabetes risk, but only in overweight individuals: results from a large female French cohort study. Eur J Epidemiol (2014) 29:831-9. doi:10.1007/s10654-014-9955-7

50. Al-Harthi SE, Alarabi OM, Ramadan WS, Alaama MN, Al-Kreathy HM, Damanhouri ZA, et al. Amelioration of doxorubicin-induced cardiotoxicity by resveratrol. Mol Med Rep (2014) 10:1455-60. doi:10.3892/ mmr.2014.2384

51. Arafa MH, Mohammad NS, Atteia HH, Abd-Elaziz HR. Protective effect of resveratrol against doxorubicin-induced cardiac toxicity and fibrosis in male experimental rats. J Physiol Biochem (2014) 70:701-11. doi:10.1007/ s13105-014-0339-y

52. Lamptey MS, Walker BL. A possible essential role for dietary linolenic acid in the development of the young rat. J Nutr (1976) 106:86-93.

53. Bacarin CC, De Sa-Nakanishi AB, Bracht A, Matsushita M, Previdelli IS, Mori $\mathrm{MA}$, et al. Fish oil prevents oxidative stress and exerts sustained antiamnesic effect after global cerebral ischemia. CNS Neurol Disord Drug Targets (2015) 14(3):400-10. doi:10.2174/1871527314666150225125232

54. Darghosian L, Free M, Li J, Gebretsadik T, Bian A, Shintani A, et al. Effect of omega-three polyunsaturated fatty acids on inflammation, oxidative stress, and recurrence of atrial fibrillation. Am J Cardiol (2015) 115:196-201. doi:10.1016/j.amjcard.2014.10.022

55. Jain AP, Aggarwal KK, Zhang PY. Omega-3 fatty acids and cardiovascular disease. Eur Rev Med Pharmacol Sci (2015) 19:441-5.

56. McEwen BJ, Morel-Kopp MC, Tofler GH, Ward CM. The effect of omega-3 polyunsaturated fatty acids on fibrin and thrombin generation in healthy subjects and subjects with cardiovascular disease. Semin Thromb Hemost (2015) 41(3):315-22. doi:10.1055/s-0034-1395352

57. Nigam A, Talajic M, Roy D, Nattel S, Lambert J, Nozza A, et al. Fish oil for the reduction of atrial fibrillation recurrence, inflammation, and oxidative stress. J Am Coll Cardiol (2014) 64:1441-8. doi:10.1016/j.jacc.2014.07.956

58. Delgado-Lista J, Perez-Martinez P, Lopez-Miranda J, Perez-Jimenez F. Long chain omega-3 fatty acids and cardiovascular disease: a systematic review. Br J Nutr (2012) 107(Suppl 2):S201-13. doi:10.1017/ S0007114512001596

59. GISSI. Dietary supplementation with n-3 polyunsaturated fatty acids and vitamin E after myocardial infarction: results of the GISSI-Prevenzione trial. (Gruppo Italiano per lo Studio della Sopravvivenza nell'Infarto miocardico). Lancet (1999) 354:447-55. doi:10.1016/S0140-6736(99)07072-5

60. Da Cunha NV, Pinge-Filho P, Panis C, Silva BR, Pernomian L, Grando $\mathrm{MD}$, et al. Decreased endothelial nitric oxide, systemic oxidative stress, and increased sympathetic modulation contribute to hypertension in obese rats. Am J Physiol Heart Circ Physiol (2014) 306:H1472-80. doi:10.1152/ ajpheart.00520.2013

61. Herrera EA, Farias JG, Gonzalez-Candia A, Short SE, Carrasco-Pozo C, Castillo RL. Omega3 supplementation and intermittent hypobaric hypoxia induce cardioprotection enhancing antioxidant mechanisms in adult rats. Mar Drugs (2015) 13:838-60. doi:10.3390/md13020838

62. Gorjao R, Azevedo-Martins AK, Rodrigues HG, Abdulkader F, ArcisioMiranda M, Procopio J, et al. Comparative effects of DHA and EPA on cell function. Pharmacol Ther (2009) 122:56-64. doi:10.1016/j. pharmthera.2009.01.004

63. Liu Y, Chen LY, Sokolowska M, Eberlein M, Alsaaty S, Martinez-Anton A, et al. The fish oil ingredient, docosahexaenoic acid, activates cytosolic phospholipase A(2) via GPR120 receptor to produce prostaglandin E(2) and plays an anti-inflammatory role in macrophages. Immunology (2014) 143:81-95. doi:10.1111/imm.12296

64. Yates CM, Calder PC, Ed Rainger G. Pharmacology and therapeutics of omega-3 polyunsaturated fatty acids in chronic inflammatory disease. Pharmacol Ther (2014) 141:272-82. doi:10.1016/j.pharmthera.2013.10.010

65. Balakumar P, Taneja G. Fish oil and vascular endothelial protection: bench to bedside. Free Radic Biol Med (2012) 53:271-9. doi:10.1016/j. freeradbiomed.2012.05.005

66. Al-Khalifa A, Maddaford TG, Chahine MN, Austria JA, Edel AL, Richard MN, et al. Effect of dietary hempseed intake on cardiac ischemia-reperfusion injury. Am J Physiol Regul Integr Comp Physiol (2007) 292:R1198-203. doi:10.1152/ ajpregu.00661.2006

67. Bellido C, Lopez-Miranda J, Blanco-Colio LM, Perez-Martinez P, Muriana FJ, Martin-Ventura JL, et al. Butter and walnuts, but not olive oil, elicit postprandial activation of nuclear transcription factor kappaB in peripheral blood mononuclear cells from healthy men. Am J Clin Nutr (2004) 80:1487-91.

68. Schwager J, Richard N, Riegger C, Salem N Jr. Omega-3 PUFAs and resveratrol differently modulate acute and chronic inflammatory processes. Biomed Res Int (2015) 2015:535189. doi:10.1155/2015/535189

69. Schwager J, Richard N, Schoop R, Wolfram S. A novel rose hip preparation with enhanced anti-inflammatory and chondroprotective effects. Mediators Inflamm (2014) 2014:105710. doi:10.1155/2014/105710

70. Shen CL, Dunn DM, Henry JH, Li Y, Watkins BA. Decreased production of inflammatory mediators in human osteoarthritic chondrocytes by conjugated linoleic acids. Lipids (2004) 39:161-6. doi:10.1007/s11745-004-1214-6

71. Hobbs T, Caso R, McMahon D, Nymark M. A novel, multi-ingredient supplement to manage elevated blood lipids in patients with no evidence of cardiovascular disease: a pilot study. Altern Ther Health Med (2014) 20:18-23.

72. WHO. Interventions on Diet and Physical Activity: What Works: Summary Report. Geneva: World Health Organization (2009).

73. Huhn S, Kharabian Masouleh S, Stumvoll M, Villringer A, Witte AV. Components of a Mediterranean diet and their impact on cognitive functions in aging. Front Aging Neurosci (2015) 7:132. doi:10.3389/fnagi.2015.00132

74. Couto E, Boffetta P, Lagiou P, Ferrari P, Buckland G, Overvad K, et al. Mediterranean dietary pattern and cancer risk in the EPIC cohort. Br J Cancer (2011) 104:1493-9. doi:10.1038/bjc.2011.106

75. Lopez-Garcia E, Rodriguez-Artalejo F, Li TY, Fung TT, Li S, Willett WC, et al. The Mediterranean-style dietary pattern and mortality among men and women with cardiovascular disease. Am J Clin Nutr (2014) 99:172-80. doi:10.3945/ajcn.113.068106

76. Lourida I, Soni M, Thompson-Coon J, Purandare N, Lang IA, Ukoumunne OC, et al. Mediterranean diet, cognitive function, and dementia: a systematic review. Epidemiology (2013) 24:479-89. doi:10.1097/EDE.0b013e3182944410

77. Valls-Pedret C, Ros E. Commentary: Mediterranean diet and cognitive outcomes: epidemiological evidence suggestive, randomized trials needed. Epidemiology (2013) 24:503-6. doi:10.1097/EDE.0b013e318296bf8e

78. Valls-Pedret C, Sala-Vila A, Serra-Mir M, Corella D, DE LA, Torre R. Mediterranean diet and age-related cognitive decline: a randomized clinical trial. JAMA Intern Med (2015) 175:1094-103. doi:10.1001/ jamainternmed.2015.1668

Conflict of Interest Statement: The authors declare that the research was conducted in the absence of any commercial or financial relationships that could be construed as a potential conflict of interest.

Copyright (c) 2015 Kakoti, Hernandez-Ontiveros, Kataki, Shah, Pathak and Panguluri. This is an open-access article distributed under the terms of the Creative Commons Attribution License (CC BY). The use, distribution or reproduction in other forums is permitted, provided the original author(s) or licensor are credited and that the original publication in this journal is cited, in accordance with accepted academic practice. No use, distribution or reproduction is permitted which does not comply with these terms. 